\title{
NSW Premier's Council for Active Living
}

\section{Peter McCue}

Premier's Council for Active Living NSW

Email:peter.mccue@heartfoundation.org.au

The NSW Premier's Council for Active Living (PCAL) aims to strengthen physical and social environments to enable active living. PCAL comprises representatives from NSW Government (linking infrastructure and service delivery agencies), business and the community sector; it reports to the Premier. The Council provides advice to government and promotes guidelines, policy and legislation to increase the level of physical activity of all people in NSW. PCAL's priorities include active travel, healthy urban planning and the liveability of NSW cities and towns.

The Council's activities are informed by better practice recommendations that highlight the need for high-level interagency collaboration as a key component of a comprehensive strategy to increase health promoting physical activity. ${ }^{1}$ Most other Australian states and territories have established similar inter-sectoral groups.

Since 2008, the Council has hosted an ongoing high-level Active Transport Roundtable with Executive representation from health, environment, transport and planning agencies. The Roundtable has led to the implementation of a number of initiatives including a new NSW State Plan Active Transport Target, the development of interagency tools such as a NSW specific Workplace Travel Plan Resource, better practice Active Travel Case Studies and a range of NSW Government policy changes such as the mandatory provision of end-of-trip facilities within NSW Government workplace refurbishments.

At the request of the NSW Premier, PCAL oversaw the development and resourcing of an updated NSW Bike Plan. An interagency governance model jointly led by the NSW Roads and Traffic Authority and the Department of Environment, Climate Change and Water was used to ensure the Bike Plan not only incorporated the development of key strategic cycling infrastructure but also actions describing how agencies will collaborate with stakeholders to implement relevant behaviour change programs. Background studies were commissioned to inform development of the Bike Plan including a cost/benefit analysis. ${ }^{2}$ Results demonstrated significant positive returns from proposed shared-pathway infrastructure development due to health, environmental (including reduced greenhouse gas emissions) and congestion co-benefits.
Another priority area in which PCAL has facilitated interagency collaboration has been the promotion of supportive urban environments for active living. PCAL has summarised in its Why Active Living Statement the key evidence demonstrating the health, environmental, economic and social benefits of physical activity and characteristics of the built environment that promote active living.

Accumulation of the evidence base linking the built environment to active living, health and greenhouse emissions has in turn led to the incorporation of evidence-based active living indicators within the Division of Local Governments Longterm Integrated Strategic Planning Reform Manual. The intention of the indicators is to provide local councils with a selection of evidence-based measures that will help demonstrate progress towards the development of more supportive environments for active living. Director-General requirements to consider active living principles within relevant State projects such as the Bonnyrigg Housing Redevelopment have also emerged.

PCAL has also developed a number of resources to facilitate implementation of Healthy Planning principles at the local government level. Designing Places for Active Living is a web-based product which provides key design considerations for walking and cycling routes, public transport, streets, open spaces, shopping centres and workplaces as well as links to key references and other resources for more detailed guidelines and specifications. NSW better practice case studies demonstrating the translation of the key design considerations into practice are also provided. Development and Active Living ${ }^{3}$ provides relevant matters (by NSW Planning Development Type) for consideration in the preparation of Local Environment Plans and Development Control Plans and in the assessment of major development applications.

Further information about PCAL, links to the PCAL resources outlined above and other active living-related tools are available at: www.pcal.nsw.gov.au

\section{References}

1. Global Advocacy Council for Physical Activity, International Society for Physical Activity and Health. The Toronto Charter for Physical Activity: A Global Call to Action. 20 May 2010. Available at: http://www.globalpa.org.uk/

2. Evaluation of the costs and benefits to the community of financial investment in cycling programs and projects in NSW. 2009. Available at: http://www.pcal.nsw.gov.au/new_nsw_ bikeplan___whats_happening

3. Development and Active Living. 2010. Available at: www.pcal. nsw.gov.au 